\title{
Decline in reported AIDS cases in Brazil after implementation of the test and treat initiative
}

\author{
Gerson Fernando Mendes Pereira ${ }^{1 *}$, Meritxell Sabidó ${ }^{1,2,3}$, Alessandro Caruso $^{1}$ and Adele Schwartz Benzaken ${ }^{1}$
}

\begin{abstract}
Background: To evaluate the trends in AIDS detection and the AIDS-attributed death rate in Brazil between 2007 and 2015 and to determine the population characteristics associated with AIDS detection.

Methods: Surveillance data including demographics, mode of HIV transmission, AIDS cases, and AIDS-attributed deaths were analysed. A logistic regression model was fitted to assess the trends in AIDS cases by mode of HIV transmission throughout the study period. A segmented Poisson regression model was used to assess changes in the trends of AIDS detection and mortality rates before (2007-2014) and after (2015) the introduction of the Test and Treat Initiative.

Results: In the segmented Poisson regression, the decline in the AIDS detection rate from 2007 to 2014 was 2.0\% annually (i.e., the odds ratio (OR) for annual decline was 0.98 (95\% [Cl: 0.98-1.00, $p$-value < 0.001). The observed AIDS detection rate in 2015 was 7.7 cases per 100,000, which was 60\% lower than the regression estimate of 19.8 for the hypothetical absence of the Test and Treat Initiative. The reduction in AIDS-attributed deaths from 2007 to 2014 was $8.0 \%$ annually (i.e., the OR for annual decline was 0.92 (95\% [Cl: 0.91-0.95, $p$-value < 0.001 ). The observed AIDS mortality rate in 2015 was 0.49 cases per 100,000, which was 73\% lower than the regression estimate of 2.1 for the hypothetical absence of the Test and Treat Initiative in 2015.

Conclusions: Our results reveal a fairly stable AIDS detection rate from 2007 to 2014, with a sudden significant drop in 2015. This drop may be related to the increasing trends in rapid testing, the number of new HIV diagnoses, the number of patients on antiretroviral therapy (ART), and a median CD4 count at ART enrolment. Further evaluation of the effects of the Test and Treat Initiative on AIDS diagnosis and mortality is needed and must be strengthened with additional data from subsequent years.
\end{abstract}

Keywords: AIDS, Mortality, Epidemiology, Trends, Brazil

\section{Background}

Approximately $42 \%$ of the people living with HIV/ AIDS (PLWHA) in Latin America can be found in Brazil [1], with 842,710 AIDS cases registered as of June 2016 [2]. An estimated 32,321 new HIV cases were reported in 2015, which corresponds to a rise of $81 \%$ since 2007 (6152) [2].

The reported number of AIDS deaths in Brazil has remained stable from 11,020 cases in 2004 to 12,298

\footnotetext{
* Correspondence: gerson.pereira@aids.gov.br

${ }^{1}$ Department of STI, AIDS and Viral Hepatitis, Secretary for Health

Surveillance, Ministry of Health Brazil, Brasília, DF, Brazil

Full list of author information is available at the end of the article
}

cases in 2015. The AIDS mortality rate has oscillated from 5.9 AIDS-related deaths per 100,000 persons in 2006 to 5.6 per 100,000 persons in 2015, although the trends present regional variations [2].

Brazil HIV/AIDS epidemic scenario concentrates in key groups and is mainly spread by sexual transmission. The country reported an HIV prevalence of $0.4 \%$ among adults in 2010. Nevertheless, the prevalence was higher in other groups such as men who have sex with men (MSM) (18.4\%) [3], sex workers (5.3\%), and drug/alcohol users $(5.9 \%)[4,5]$. The majority of AIDS cases are men, with a sex ratio of 1.7 to one in 2012. Amongst men, heterosexual transmission increased in the 1990s, but

(C) The Author(s). 2019 Open Access This article is distributed under the terms of the Creative Commons Attribution 4.0 International License (http://creativecommons.org/licenses/by/4.0/), which permits unrestricted use, distribution, and 
MSM still account for the majority of AIDS cases (36.5\%) occurring amongst males [2].

By age, most are AIDS cases are in those 25 to 49-years old. The age group 13-19 years is the only one with more women than men affected by AIDS [2]. One-third of AIDS cases hit those with incomplete primary schooling. The risk of HIV/AIDS presents a geographical gradation, with southern states having a larger proportion of PLWHA [2].

Brazil implemented the Test and Treat Initiative following the release of the Clinical Protocol and Therapeutic Guidelines for HIV Infection Management in Adults (CPTG) in 2013 [6]. After adopting the protocol, the percentage of PLWHA who were treated with antiretroviral therapy (ART) increased from 44\% in 2012 to $55 \%$ in 2015, resulting in 455,000 PLWHA undergoing ART in 2015 [7]. It should be noted that the ART eligibility criteria have evolved over time. In 2001, ART was initiated in patients with CD4 counts $<350$ cells $/ \mathrm{mm}^{3}$, regardless of symptoms or viral load [8]. ART initiation criteria for adult and adolescent patients consisted of a CD4 count $\leq 500$ cells $/ \mathrm{mm}^{3}$ until 2013 and initiation regardless of CD4 count thereafter [9]. The expansion of ART eligibility will help meet the target of $90 \%$ of patients receiving ART by 2020. Although access to ART has expanded in recent years, only $80 \%$ of HIV-infected people who knew their HIV status were receiving treatment at the end of 2015 [10].

To accelerate efforts towards ending the AIDS epidemic, Brazil adopted the 90-90-90 and 95-95-95 targets in 2014. The 90-90-90 target calls for 90\% of the people living with HIV to be diagnosed, $90 \%$ of the diagnosed people to be receiving sustained ART, and viral suppression in $90 \%$ of patients on ART by 2020 [7]. The 90-90-90 and the subsequent 95-95-95 by 2030 targets translate into 84 and $54 \%$ of patients being diagnosed and virally supressed amongst PLWHA, respectively [10]. Critical efforts to achieve these targets include scaling up access to prevention, diagnosis, and treatment; combating stigma and discrimination; and promoting human rights, particularly to the key populations affected by the epidemic and people living with HIV. These efforts have been mobilized through the Unified Health System (Sistema Único de Saúde - SUS), although civil society organizations have also played a prominent role [7].

Understanding the evolution of AIDS incidence and mortality is relevant to the response to HIV/AIDS. We used data generated from the surveillance system to reconstruct the pattern of AIDS detection and the AIDS-attributed mortality rate in Brazil. In addition, we examined linkages between AIDS detection and sociodemographic factors.

\section{Methods}

\section{Setting}

Brazil has a publicly funded healthcare system based on universal access to health services that fully subsidizes access to medical services, centralized laboratory monitoring, and access to ART. ART is distributed centrally, and patients primarily attend tertiary care hospitals in capital cities.

\section{Data sources}

We analysed AIDS cases and related variables reported to the Brazilian surveillance system from 2007 to 2015 . Data was obtained from several electronic surveillance subsystems: 1) the Notifiable Disorders Information System [Sistema de Informação de Agravos de Notificação (SINAN)]: AIDS cases, epidemiological characteristics (eg, sex, age); 2) the Mortality Information System [Sistema de Informaçoes sobre Mortalidade (SIM)]: death information such as cause of death, the date, and the municipality of death were recorded from the declaration of death document; 3) the Logistic Treatment Control System [Sistema de Controle Logistico de Medicamentos (Siclom)]; and 4) the Laboratory Testing Information System [Sistema de Informação de Exames Laboratoriais (Siscel)].

\section{Study population}

The national AIDS definition was used to report AIDS cases to the national surveillance system [11]. This definition was revised in 2003 to include a CD4 cell count less than 350 cells $/ \mathrm{mm}^{3}$. Until 2003, HIV testing was performed by enzyme-linked immunosorbent assay (ELISA). All positive results were confirmed with a second ELISA and Western blot. After 2003, two rapid tests were performed sequentially on different finger prick specimens. If the results between the two tests were discordant, the testing was repeated. We included cases that were at least 15 years of age.

\section{Data collection}

Age, sex, mode of HIV exposure, education level, vital status, race/colour, and date of AIDS diagnosis were collected. The potential mode of HIV transmission was determined based on several variables: 1) sexual activity of the following categories: sex with men, sex with women, sex with men and women, no sexual transmission; 2) intravenous drug users (IDUs) (Yes/No/Unknown); 3) haemophilia treatment or transfusion (Yes/No/Unknown); 4) vertical transmission (Yes/No/Unknown); and 5) biological material accident with seroconversion within 6 months (Yes/No/Unknown). Death was determined based on the recorded date of death. Key indicators related to the cascade of HIV care, such as the number of rapid tests, the number of new HIV 
diagnoses, the number of PLWHA on ART, and the median CD4 count at ART enrolment, were obtained from national programme data [10].

\section{Statistical analysis}

Stata V11.0 (StataCorp LP, College Station, TX, USA) was used for the analysis. Data was described using frequencies or percentages or means with standard deviations (SDs).

Population estimates were obtained for the years 2007-2015 to calculate mortality and AIDS rates (per 100,000). These estimates were obtained from the Institute of Statistics in Brazil (IBGE - Instituto Brasileiro de Geografia e Estatística). Trends in the AIDS detection rate were evaluated by sex and age group, and trends in the AIDS detection rate and AIDS-attributed death rates were evaluated by sex. Trends in sociodemographic characteristics, mode of HIV exposure, and death were evaluated according to the proportion of AIDS diagnoses over time. The analysis of the mode of HIV exposure was conducted separately for heterosexuals, homosexual/bisexual men, IDUs, vertical transmission, and others. Homosexual/bisexual men were defined as men who reported having sex with men or with men and women as the potential exposure route. IDUs were participants who reported this as the potential transmission route. Participants who reported sexual intercourse with the other sex as the potential exposure route were classified as heterosexuals; homosexual/bisexual women were included in this group. Homosexual/bisexual men and heterosexuals with a history of being IDUs were part of the homosexual/bisexual men, heterosexual, and IDU analyses. The "others" mode of transmission included transfusion, biological accidents, and haemophilia.

The Test and Treat Initiative was adopted in December 2013 and implemented during 2014. Changes in the trends of the AIDS detection rate and the AIDS mortality rate after the introduction of the Test and Treat Initiative in relation to the period before the intervention (2007-2014) were assessed through a segmented regression Poisson model of an interrupted time series. The year 2015 was used as the interruption year for the interrupted trend regression analysis [12]. A continuation of the pre-intervention trend over time (20072014) was estimated throughout 2015 as if Test and Treat had not been implemented. A $p$-value $<0.05$ was considered significant.

\section{Ethics}

This analysis is part of the Ministry of Health's strategic plan to enhance HIV testing and was not assessed by an ethical committee board. In Brazil, according to law CFM n ${ }^{\circ} 1.865 / 96$, authorization or consent from parents or a responsible person is not required to perform an
HIV test on individuals over 12 years of age if the test is voluntary and consent is provided by the adolescent, provided that the adolescent has the capacity to evaluate their problem and take actions accordingly. Administrative permission to access the raw data of the datasources used were obtained from the Department of STI, AIDS and Viral Hepatitis of the Brazilian Ministry of Health.

\section{Results}

\section{Sample characteristics}

From January 2007 to December 2015, a total of 329,154 AIDS cases were registered in the national surveillance system. The mean patient age was 38.0 years (SD: 11.5 ), and $63.2 \%$ were men. Table 1 describes the study population in terms of demographic characteristics, mode of HIV transmission, and death, stratified by sex.

Heterosexual intercourse was reported as the mode of transmission in 60.7 and $33.8 \%$ of AIDS cases in women and men, respectively. Overall, $25.3 \%$ of AIDS cases were reported in homosexual/bisexual men. AIDS cases due to IDU represented $2.5 \%$ of cases in women and $6.0 \%$ of cases in men. In both sexes, a small proportion of cases $(<1 \%)$ occurred via vertical transmission and other modes of HIV exposure. Regarding the level of education, the highest proportions of cases were found in women with incomplete post-secondary education (43.4\%) and in patients with at least a post-secondary education (40.0\%). The highest proportion of AIDS cases was found in white people (45.9\% in women; $49.1 \%$ in men), followed by brown people $(40.6 \%$ in women; $40.0 \%$ in men). Death occurred in $15.7 \%$ of female cases and $18.5 \%$ of male cases.

\section{Changes in the AIDS detection and AIDS-attributed death rates over time}

The AIDS detection rate (per 100,000) before the Test and Treat Initiative (2007-2014) was 20.45; right after its implementation (2015), this rate was 7.70 (Fig. 1), which represents an approximately $62 \%$ crude decrease. In the segmented Poisson regression, the decline over 2007-2014 was $2.0 \%$ annually (i.e., the odds ratio (OR) for annual decline was 0.98 (95\% [CI: 0.98-1.00, $p$-value $<0.001$ ), and the predicted AIDS detection rate in 2015 without implementation of the Test and Treat Initiative in 2015 would have been 19.8. Thus, the estimated drop in 2015 (adjusted for the pre-2015 trend) was (1-7.7/ 19.8) $=60 \%$.

The mortality rate was 2.32 (per 100,000) before the Test and Treat Initiative (2007-2014); right after its implementation (2015) (Fig. 2), the rate was 0.49, which represents a crude decline of $79 \%$. In the segmented Poisson regression, the decline over 2007-14 was $8.0 \%$ annually (i.e., the OR for annual decline was 0.92 (95\% [CI: 0.91-0.95, $p$-value <0.001), and the 
Table 1 Characteristics of cumulative known HIV cases (alive and death) by sex, Brazil, 2007-2015

\begin{tabular}{|c|c|c|c|c|}
\hline & \multicolumn{2}{|c|}{ Female $(n=120,974)$} & \multicolumn{2}{|c|}{ Male $(n=208,002)$} \\
\hline & $n$ & $\%$ & $\mathrm{n}$ & $\%$ \\
\hline \multicolumn{5}{|l|}{ Age, years $(n=328,372)$} \\
\hline $15-24$ & 12,944 & 10.7 & 21,184 & 10.2 \\
\hline $25-34$ & 37,592 & 31.2 & 68,413 & 32.9 \\
\hline $35-44$ & 35,954 & 29.8 & 62,956 & 30.3 \\
\hline $45-54$ & 22,482 & 18.6 & 37,572 & 18.1 \\
\hline$\geq 55$ & 11,671 & 9.7 & 17,604 & 8.5 \\
\hline \multicolumn{5}{|l|}{ Mode of HIV exposure } \\
\hline Heterosexual $(n=328,976)$ & 73,417 & 60.7 & 70,291 & 33.8 \\
\hline Homosexual/bisexual men $(n=208,002)$ & NA & NA & 52,605 & 25.3 \\
\hline IDU $(n=198,452)$ & 1801 & 2.5 & 7484 & 6.0 \\
\hline Vertical transmission $(n=225,593)$ & 616 & 0.8 & 748 & 0.5 \\
\hline Others $(n=328,976)$ & 678 & 0.6 & 863 & 0.4 \\
\hline \multicolumn{5}{|l|}{ Level of education ( $n=149,572)$} \\
\hline Incomplete primary school & 2120 & 3.8 & 2730 & 2.9 \\
\hline Incomplete secondary school & 13,011 & 23.6 & 18,143 & 19.2 \\
\hline Incomplete post-secondary school & 23,937 & 43.4 & 35,731 & 37.9 \\
\hline z Complete post-secondary school & 16,115 & 29.2 & 37,785 & 40.0 \\
\hline \multicolumn{5}{|l|}{ Race/colour $(n=199,044)$} \\
\hline White & 31,983 & 45.9 & 63,455 & 49.1 \\
\hline Black & 8867 & 12.7 & 13,037 & 10.1 \\
\hline Asian & 335 & 0.5 & 678 & 0.5 \\
\hline Brown (Pardo) & 28,294 & 40.6 & 51,759 & 40.0 \\
\hline Indigenous & 253 & 0.4 & 383 & 0.3 \\
\hline Death, any cause $(n=234,809)$ & 12,973 & 15.7 & 28,208 & 18.5 \\
\hline
\end{tabular}

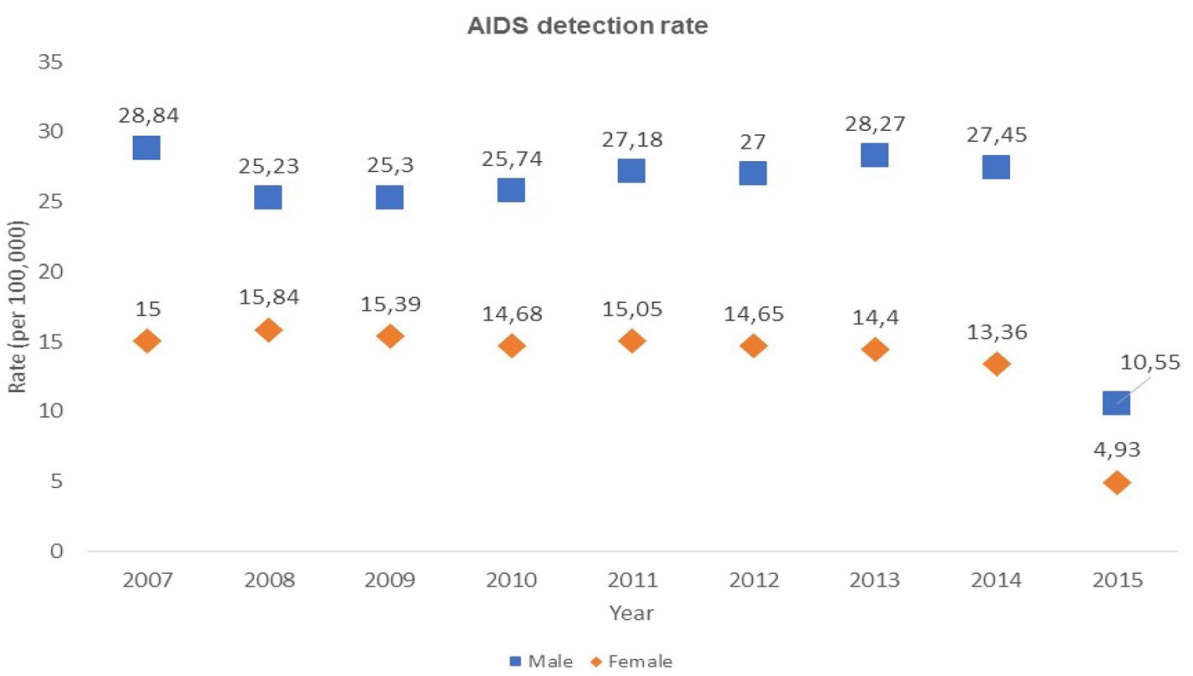

Fig. 1 Trends in AIDS detection rates by sex and by treatment status, Brazil 2007-2015 


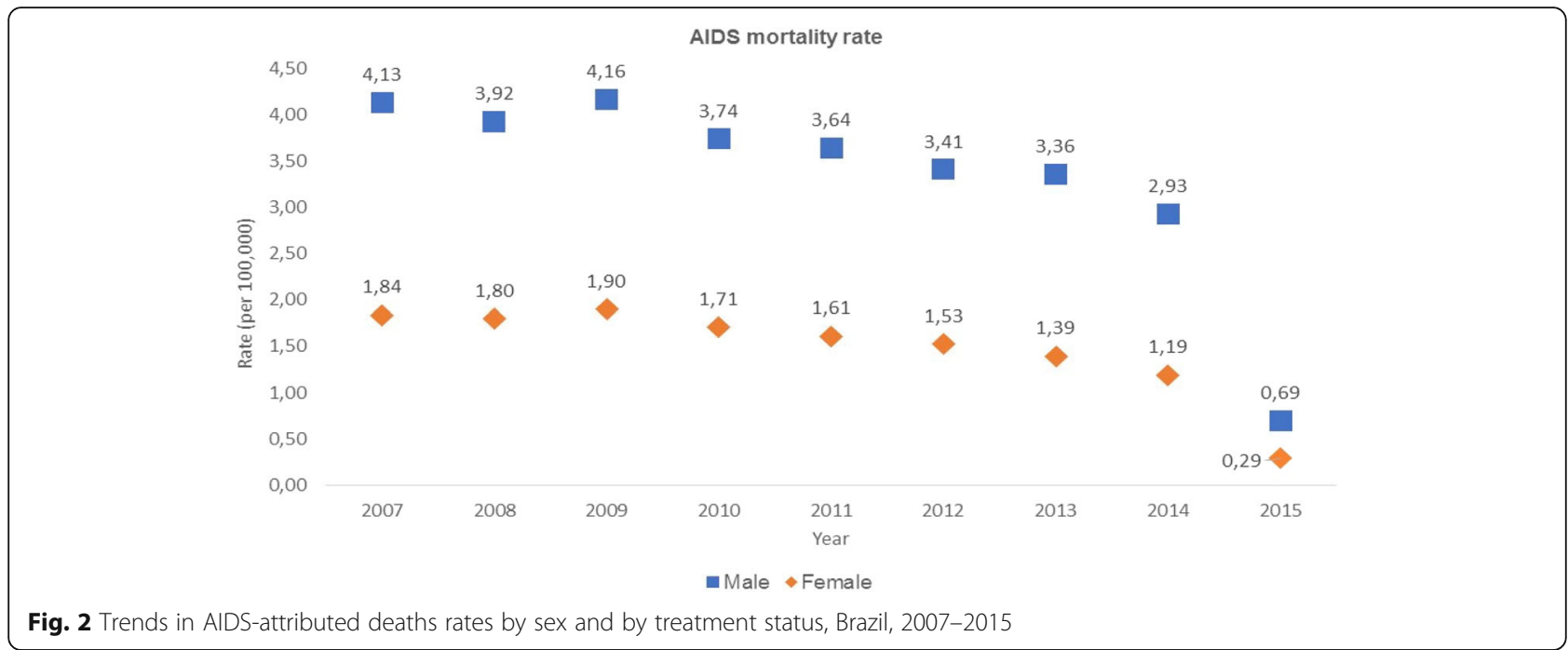

predicted AIDS mortality rate in 2015 without implementation of the Test and Treat Initiative in 2015 would have been 2.1. Thus, the estimated drop in 2015 (adjusted for pre-2015 trend) was (1-0.49/ $2.2)=73 \%$.

\section{Modes of HIV exposure amongst reported AIDS cases}

The proportions of reported AIDS cases amongst heterosexuals were stable in the first few years and then declined in men after 2010 and in women only after 2013 (Table 2). The proportion of cases reported in homosexual/bisexual men increased over time but declined in the final 2 years. The proportion of AIDS cases caused by IDU decreased in both sexes, although the decline was more pronounced in men (from $9.0 \%$ in 2007 to $3.5 \%$ in 2015) than in women (from $3.1 \%$ in 2007 to $2.2 \%$ in
2015). An increasing trend in vertical transmission was observed for the proportion of AIDS cases in both sexes. A decrease was observed in the proportion of reported AIDS cases caused by other modes of transmission (less than $1 \%$ in both sexes).

\section{Key indicators of the cascade of HIV care}

Table 3 displays key indicators related to the cascade of HIV care over time. The number of PLWHA on ART increased from 181,000 people in 2007 to more than 455,000 people in 2015. The median CD4 of PLWHA enrolling in ART also increased from 390 cells $/ \mathrm{mm}^{3}$ in 2013 to 416 cells $/ \mathrm{mm}^{3}$ in 2015 . The number of rapid tests and new HIV diagnoses also increased over time, with an acceleration beginning in 2013.

Table 2 Mode of HIV exposure amongst reported AIDS cases by sex, Brazil, 2007-2015 (\%)

\begin{tabular}{|c|c|c|c|c|c|c|c|c|c|}
\hline & 2007 & 2008 & 2009 & 2010 & 2011 & 2012 & 2013 & 2014 & 2015 \\
\hline \multicolumn{10}{|l|}{ Female } \\
\hline$n$ & 14,474 & 15,350 & 15,023 & 14,326 & 14,826 & 14,526 & 14,298 & 13,259 & 4892 \\
\hline Heterosexual & 59.0 & 59.7 & 61.3 & 63.6 & 62.8 & 63.2 & 62.4 & 57.9 & 47.1 \\
\hline IDU & 3.1 & 2.8 & 2.5 & 2.6 & 2.4 & 2.6 & 1.9 & 2.3 & 2.2 \\
\hline Vertical transmission & 0.5 & 0.7 & 0.7 & 0.9 & 0.50 & 0.7 & 0.8 & 0.9 & 1.2 \\
\hline Others & 0.9 & 0.7 & 0.7 & 0.50 & 0.5 & 0.4 & 0.5 & 0.4 & 0.4 \\
\hline \multicolumn{10}{|l|}{ Male } \\
\hline$n$ & 22,222 & 23,534 & 23,835 & 24,087 & 25,633 & 25,685 & 26,884 & 26,094 & 10,028 \\
\hline Heterosexual & 35.0 & 34.5 & 35.0 & 35.9 & 35.0 & 34.7 & 33.3 & 30.9 & 25.3 \\
\hline Homosexual/bisexual men & 21.4 & 21.8 & 23.5 & 25.3 & 26.5 & 28.1 & 27.8 & 27.6 & 23.1 \\
\hline IDU & 9.0 & 7.9 & 7.3 & 6.0 & 5.7 & 4.7 & 4.5 & 4.0 & 3.5 \\
\hline Vertical transmission & 0.3 & 0.4 & 0.4 & 0.5 & 0.5 & 0.5 & 0.6 & 0.7 & 0.8 \\
\hline Others & 0.6 & 0.6 & 0.5 & 0.4 & 0.3 & 0.4 & 0.33 & 0.3 & 0.3 \\
\hline
\end{tabular}


Table 3 Key indicators related to the cascade of HIV care over time, Brazil, 2007-2015 (\%)

\begin{tabular}{llllllllll}
\hline & 2007 & 2008 & 2009 & 2010 & 2011 & 2012 & 2013 & 2014 & 2015 \\
\hline HIV rapid tests distributed & $1,225,175$ & $1,754,335$ & $2,446,380$ & $1,680,940$ & $2,307,615$ & $3,750,400$ & $4,729,485$ & $6,492,105$ & $8,533,270$ \\
New HIV diagnoses & 6152 & 6654 & 7126 & 8316 & 9863 & 11,223 & 16,331 & 26,277 & 32,321 \\
PLWHA alive on ART $^{\mathrm{a}}$ & 181,000 & 193,000 & 231,000 & 257,000 & 284,000 & 313,000 & 355,000 & 410,000 & 455,000 \\
Median CD4 count & NA $^{\mathrm{c}}$ & NA $^{\mathrm{c}}$ & 361 & 364 & 374 & 379 & 390 & 404 & 416 \\
New AIDS cases & 36,632 & 38,813 & 38,812 & 38,340 & 40,395 & 40,160 & 41,125 & 39,330 & 14,941 \\
\hline
\end{tabular}

${ }^{a}$ Between 1999 and 2008, the number of people living with HIV (PLWHA) in ART was estimated considering the number of dispensations performed in December of each year. As of 2009, PLWHA in ART are those that have had at least one ARV dispensation in the last 100 days of the year. ${ }^{\mathrm{b}}$ Median CD4 count (cell/mm ${ }^{3}$ ) of PLWHA enrolling in ART. ' NA: Data not available because the Logistic Treatment Control System [Sistema de Controle Logistico de Medicamentos (Siclom)] was in an implementation stage, which influenced the data quality

\section{Discussion}

This study provides an overview of 9-year trends in the detection of AIDS cases in Brazil. Our findings show that the AIDS detection rate remained stable from 2007 to 2014 but displayed a significant decline the following year (2015). This decline was observed in both sexes. This change might be explained by the adoption of the Test and Treat Initiative in December 2013 and its subsequent implementation in 2014, offering early treatment to all HIV-positive adults, regardless of their CD4 cell counts or viral load; in this context, treatment is also used as a form of prevention (TasP).

TasP is likely the major driver of the reductions in AIDS morbidity and mortality. Amongst treated HIV-infected patients, ART leads to immune reconstitution, preventing the emergence of AIDS events and death [13-15].

Brazil adopted the Test and Treat Initiative two years ahead of the standard WHO "test and wait", which was modified in 2015. The early adaption in Brazil correlated with increases in HIV diagnoses and patients receiving treatment; therefore, the initiative might be a major driver behind the observed reduction in AIDS cases. The number of HIV rapid tests increased over time, with acceleration from 2012. Likewise, the number of new HIV diagnoses and the number of PLWHA on ART (reflecting improved survival) showed increasing trends with acceleration from 2013 [10]. As emphasized by the WHO's 2013 consolidated guidelines, early ART initiation is essential to leverage the full range of benefits that ART offers [16]. Brazil has displayed a shift towards earlier initiation of ART, as demonstrated by the increase in the proportion of patients with pre-ART CD4 cell counts above 500 cells $/ \mathrm{mm}^{3}$ (from $17 \%$ in 2013 to $37 \%$ in 2016) [10]. The median CD4 of PLWHA enrolling in ART has also increased over time with acceleration after 2013 [10]. This increase suggests that the Test and Treat Initiative was effective.

The significant decrease in AIDS-attributed deaths in the final year might also be attributed to the TasP strategy [13-15]. Scaling up ART is strongly and significantly associated with population-level decreases in all-cause mortality amongst HIV-infected individuals [17]. It is unlikely that pre-exposure prophylaxis (PrEP) plays a role in the results of this study. In Brazil, the first steps for offering PrEP on a large scale started in 2013, when the Ministry of Health funded 5 separate small-scale PrEP demonstration projects [18]. PrEP distribution for HIV prevention in key higher-risk population groups throughout 35 sites across the country only started in January 2018. As of April 2018, the estimated number of current PrEP users was 1000-1500, and it is estimated that in this first year, 9000 patients will benefit from PrEP.

Brazil has adopted combination prevention, which is a strategy that involves post-exposure prophylaxis (PEP); PrEP; mass campaigns to encourage condom use and testing; distribution of condoms; and specific HIV prevention actions with key populations [7]. Indeed, increasing access to prevention and diagnosis, particularly for the key populations affected by the epidemic, was key to the success of the Test and Treat strategy. Standing out amongst these efforts is the programme Viva Melhor Sabendo (Live Better Knowing), which was implemented in 2013 [7]. The programme consists of outreach peer prevention intervention that offers rapid oral fluid HIV testing in the community [19]. The Department of Sexually Transmitted Infections, AIDS, and Viral Hepatitis has worked closely with civil society organizations to implement this programme. This close collaboration has been also essential to link HIV cases detected with the health system [19]. Between January 2013 and April 2016, 43,358 participants were tested, and roughly half $(52.1 \%)$ were tested for HIV first time ever [20]. These results suggest that the programme is reaching people with low access to testing and who might belong to high-risk groups [20]. However, efforts are still needed to promote testing, particularly amongst the most vulnerable groups.

A major challenge for the country will be expanding periodic HIV testing, specifically by targeting the most at-risk populations. To expand ART for HIV-infected individuals and increase survival, estimates of HIV incidence must be incorporated into HIV/AIDS surveillance activities [21]. 
The period of 2007 to 2013 displayed an increasing trend in the AIDS detection rate in men. When assessed by education, there was found to be an increase only in well-educated people. Changing patterns of risk behaviours could have influenced our results. Notably, there was a significant increase in diagnosed AIDS cases amongst homosexual/bisexual men in Brazil; this population is driving the HIV epidemic in the south of the country. It is likely that the intense macho culture that prevails discourages homosexual/bisexual men from identifying as such and therefore from adopting preventive measures. Brazil began distributing PrEP in January 2018 as part of their combined prevention initiatives [7], and homosexual/bisexual men are a key population that may benefit.

By contrast, AIDS cases in IDUs have significantly decreased over time. In Brazil, IDU has been progressively supplanted by crack cocaine. However, $5 \%$ of crack users in Brazil have HIV-AIDS, a rate 12 times higher than that of the general population [7].

AIDS cases amongst indigenous people have remained low and stable. In all age groups, AIDS was more prevalent amongst men than women. The age group most affected was 25- to 44-year-olds.

We have analysed data on AIDS cases reported to the national surveillance system, which is subject to some limitations. We cannot rule out the underreporting of AIDS cases and AIDS-attributed deaths rates, particularly in a context where a substantial number of infected subjects are unaware of their HIV status. Mortality may have multiple causes, and determining the attribution of HIV or other aetiologies is difficult.

\section{Conclusions}

In conclusion, our results show fairly stable levels of AIDS detection rate and of AIDS-attributed deaths over 2007-2014, with sudden significant drops in 2015. The drop in the AIDS detection rate might be related to the scale-up of HIV rapid testing (increasing number, with a more rapid increase beginning in 2012), the increasing trend in the number of PLWA on ART, which reflects improved survival (with a more rapid increase beginning in 2013) and the median CD4 count at ART enrolment (increasing, with a more rapid increase beginning in 2013). Given that the reduction in the number of AIDS diagnoses is apparent for only one year thus far, this observation and its interpretation require further confirmation and must be strengthened with similar analyses using additional years of data (2016 and 2017). Future studies could explore whether this decrease leads to a reduction in HIV transmission at the population level [17].

Brazil must continue expanding ART and achieving universal access to therapy. Although gains in ART coverage have been reported, ART-eligible individuals in northern Brazil are notably less likely to obtain ART than those in southern Brazil. Other improvements, such as improved availability of the combined triple-dose, 3-in-1 medication, and use of the preferred first-line regimen in 2015, might enhance the decreasing trends in the AIDS detection and AIDS-attributed death rates.

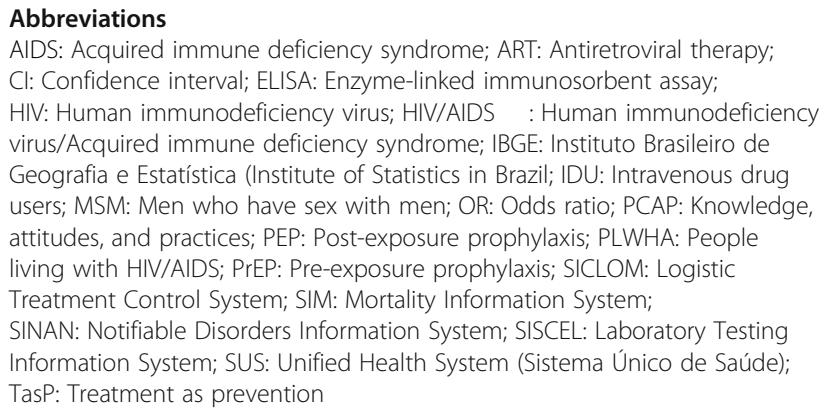

\section{Acknowledgements}

We thank the government officials, health professionals, and patients who participated in this study.

\section{Funding}

The Department of STI, AIDS, and Viral Hepatitis of the Brazilian Ministry of Health funded the study. The Department of STI, AIDS, and Viral Hepatitis is responsible for the data collection as part of their regular activities. Members of the Department are co-authors and participated in the interpretation of data.

\section{Availability of data and materials}

Data will not be shared since they belong to the government of Brazil and data permits applications apply for each new study.

\section{Authors' contributions}

MS designed the study, analysed the data, and wrote the article; GFMP and AC collected the data; ASB, GFMP, MS, and AC interpreted the data. All authors critically revised the manuscript for important intellectual content and gave final approval for this version to be published.

\section{Ethics approval and consent to participate}

This analysis is part of the Ministry of Health strategic plan to enhance HIV testing and was not assessed by an ethical committee board. In Brazil, according to law CFM n 1.865/96, authorization or consent from parents or a responsible person is not required to perform an HIV test in individuals over 12 years of age if the test is voluntary and consent is provided by the adolescent, provided that the adolescent has the capacity to evaluate their problem and take actions accordingly. Administrative permissions to access the raw data of the datasources used were obtained from the Department of STI, AIDS and Viral Hepatitis of the Brazilian Ministry of Health. The datasets analysed during the current study are not publicly available due data ownership of the Brazilian Ministry of Health. For data permits, please contact the Department of the Department of STI, AIDS and Viral Hepatitis of the Brazilian Ministry of Health.

\section{Consent for publication}

Not applicable.

\section{Competing interests}

The authors declare that they have no competing interests.

\section{Publisher's Note}

Springer Nature remains neutral with regard to jurisdictional claims in published maps and institutional affiliations. 


\section{Author details}

'Department of STI, AIDS and Viral Hepatitis, Secretary for Health Surveillance, Ministry of Health Brazil, Brasilia, DF, Brazil. ${ }^{2}$ TransLab, Department of Medical Sciences, Universitat de Girona, Catalonia, Spain

${ }^{3}$ CIBER Epidemiology and Public Health (CIBERESP), Madrid, Spain.

Received: 7 July 2017 Accepted: 25 April 2019

Published online: 04 July 2019

\section{References}

1. The Joint United Nationals Programme on HIV/AIDS/World Health Organization (UNAIDS/WHO). The prevention gap report: UNAIDS; 2016. Available from: http://www.unaids.org/sites/default/files/media_asset/2016prevention-gap-report_en.pdf

2. Brazil Ministry of Health: Secretariat of Health Surveillance, Department of STI, AIDS and Viral Hepatitis. [Epidemiological Bulletin HIV/AIDS], Brasília 2016. Year $V-n^{\circ} 1$ - until epidemiological week 26th (January-June 2016. Brasília: 2016. Available from: http://www.aids.gov.br/sites/default/files/ anexos/publicacao/2016/59291/boletim_2016_1_pdf_16375.pdf

3. Kerr L, Kendall C, Guimaraes MDC, Salani Mota R, Veras MA, Dourado I, Maria de Brito A, Merchan-Hamann E, Pontes AK, Leal AF, et al. HIV prevalence among men who have sex with men in Brazil: results of the 2nd national survey using respondent-driven sampling. Medicine (Baltimore). 2018:97(1S Suppl 1):S9-S15.

4. Bastos Fl. Rates of HIV infection and syphilis and inventory of knowledge, attitudes and risk practices related to sexually transmitted infections among drug users in 10 brazilian municipalities. In: Technical report presented to the department of STD, AIDS and viral hepatitis; 2009.

5. Ferreira-Junior ODC, Guimaraes MDC, Damacena GN, de Almeida WDS, de Souza-Junior PRB, Szwarcwald CL, Brazilian FSWG. Prevalence estimates of HIV, syphilis, hepatitis B and C among female sex workers (FSW) in Brazil, 2016. Medicine (Baltimore). 2018;97(1S Suppl 1):S3-8.

6. Brazilian Ministry of Health: Secretariat of Health Surveillance, Department of STI, AIDS and viral hepatitis. [Clinical protocol and therapeutic guidelines for management of HIV infection in adults]. Available from: http://www.aids. gov.br/tags/publicacoes/protocolo-clinico-e-diretrizes-terapeuticas

7. Brazil Ministry of Health: Secretariat of Health Surveillance, Department of STI, Aids and Viral Hepatitis. The brazilian response to HIV and AIDS. Global AIDS Response Progress Reporting. Narrative Report 2015]. Available from: http://www.unaids.org/sites/default/files/country/documents/BRA_narrative_ report_2015.pdf

8. Brazilian Ministry of Health: [Recommendations for antiretroviral treatment for adults and adolescents with HIV-2001]. Brasília, DF: Brazilian Ministry of Health; 2001.

9. Brazilian Ministry of Health: Secretariat of Health Surveillance, Department of STI, Aids and Viral Hepatitis. Clinical protocol and therapeutic guidelines for management of HIV infection in children and adolescents. Brasília, DF: Brazilian Ministry of Health; 2014. Available from: http://www.aids.gov.br/ sites/default/files/anexos/publicacao/2014/55939/08_05_2014_protocolo_ pediatrico_pdf_36225.pdf. Accessed 2 May 2015

10. Brazil Ministry of Health: Secretariat of Health Surveillance, Department of STI, AIDS and Viral Hepatitis. [Report of Clinical Monitoring]. Brasilia: Ministry of Health; 2017. Available at: http://www.aids.gov.br/pt-br/pub/2017/ relatorio-de-monitoramento-clinico-do-hiv

11. Brazilian Ministry of Health. Secretariat of Health Surveillance, Department of STI, Aids and Viral Hepatitis. [Criteria to define AIDS cases in adult and children]. Brasilia: Brazilian Ministry of Health, 2004. Available at: http:/www. aids.gov.br/sites/default/files/criterios_aids_2004.pdf

12. Lopez Bernal J, Cummins S, Gasparrini A. Interrupted time series regression for the evaluation of public health interventions: a tutorial. Int J Epidemiol. 2017:48-355.

13. Group TAS, Danel C, Moh R, Gabillard D, Badje A, Le Carrou J, Ouassa T, Ouattara E, Anzian A, Ntakpe JB, et al. A trial of early Antiretrovirals and isoniazid preventive therapy in Africa. N Engl J Med. 2015;373(9):808-22.

14. Group ISS, Lundgren JD, Babiker AG, Gordin F, Emery S, Grund B, Sharma S, Avihingsanon A, Cooper DA, Fatkenheuer G, et al. Initiation of antiretroviral therapy in early asymptomatic HIV infection. N Engl J Med. 2015;373(9):795-807.

15. Cohen MS, Chen YQ, McCauley M, Gamble T, Hosseinipour MC, Kumarasamy N, Hakim JG, Kumwenda J, Grinsztejn B, Pilotto JH, et al.
Prevention of HIV-1 infection with early antiretroviral therapy. N Engl J Med. 2011:365(6):493-505.

16. World Health Organisation (WHO): Consolidated guidelines on the use of antiretroviral drugs for treating and preventing HIV infection. Geneva, 2013. Available at: http://www.who.int/hiv/pub/guidelines/arv2013/download/en/

17. Montaner JS, Lima VD, Harrigan PR, Lourenco L, Yip B, Nosyk B, Wood E, Kerr T, Shannon K, Moore D, et al. Expansion of HAART coverage is associated with sustained decreases in HIV/AIDS morbidity, mortality and HIV transmission: the "HIV treatment as prevention" experience in a Canadian setting. PLoS One. 2014;9(2):e87872.

18. Pan American Health Organisation (PAHO): Web bulletins. Brazil initiated the implementation of PrEP to prevent new cases of HIV among key higher-risk population groups. Available from: https://www.paho.org/hq/index. php?option=com_content\&view=article\&id=14039\&ltemid=135\&lang=fr

19. Pascom ARP, Habckost CB, Lobo TDM, Pasini EN, Comparini RA, Mesquita FC. Expanding HIV testing among key populations in Brazil: a peer pointofcare testing project experience. Bull World Health Organ. 2016;94(8): 263-270.

20. de Barros CHD, Sabidó M, de Miranda Lobo TD, Pascom RP, Pasini E, Mesquita F, Benzaken A. Community-based rapid HIV testing in Brazil for vulnerable populations: whom are we reaching? J AIDS Clin Res. 2017:8:1000679

21. Ndawinz JD, Costagliola D, Supervie V. New method for estimating HIV incidence and time from infection to diagnosis using HIV surveillance data: results for France. AIDS. 2011;25(15):1905-13.

\section{Ready to submit your research? Choose BMC and benefit from:}

- fast, convenient online submission

- thorough peer review by experienced researchers in your field

- rapid publication on acceptance

- support for research data, including large and complex data types

- gold Open Access which fosters wider collaboration and increased citations

- maximum visibility for your research: over $100 \mathrm{M}$ website views per year

At BMC, research is always in progress.

Learn more biomedcentral.com/submissions 